\title{
Opportunistic evaluation of modelled sea ice drift using passively drifting telemetry collars in Hudson Bay, Canada
}

\author{
Ron R. Togunov ${ }^{1,2}$, Natasha J. Klappstein ${ }^{3}$, Nicholas J. Lunn ${ }^{4}$, Andrew E. Derocher ${ }^{3}$, and Marie Auger-Méthée, \\ ${ }^{1}$ Department of Zoology, University of British Columbia, Vancouver, BC V6T 1Z4, Canada \\ ${ }^{2}$ Institute for the Oceans and Fisheries, University of British Columbia, Vancouver, BC V6T 1Z4, Canada \\ ${ }^{3}$ Department of Biological Sciences, University of Alberta, Edmonton, AB T6G 2E9, Canada \\ ${ }^{4}$ Wildlife Research Division, Science and Technology Branch, Environment and Climate Change Canada, \\ CW-422 Department of Biological Sciences, University of Alberta, Edmonton, AB T6G 2E9, Canada \\ ${ }^{5}$ Department of Statistics, University of British Columbia, Vancouver, BC V6T 1Z4, Canada
}

Correspondence: Ron R. Togunov (r.togunov@oceans.ubc.ca)

Received: 21 January 2020 - Discussion started: 27 February 2020

Revised: 12 May 2020 - Accepted: 15 May 2020 - Published: 15 June 2020

\begin{abstract}
Sea ice drift plays a central role in the Arctic climate and ecology through its effects on the ice cover, thermodynamics, and energetics of northern marine ecosystems. Due to the challenges of accessing the Arctic, remote sensing has been used to obtain large-scale longitudinal data. These data are often associated with errors and biases that must be considered when incorporated into research. However, obtaining reference data for validation is often prohibitively expensive or practically unfeasible. We used the motion of 20 passively drifting high-accuracy GPS telemetry collars originally deployed on polar bears, Ursus maritimus, in western Hudson Bay, Canada, to validate a widely used sea ice drift dataset produced by the National Snow and Ice Data Center (NSIDC). Our results showed that the NSIDC model tended to underestimate the horizontal and vertical (i.e., $u$ and $v$ ) components of drift. Consequently, the NSIDC model underestimated magnitude of drift, particularly at high ice speeds. Modelled drift direction was unbiased; however, it was less precise at lower drift speeds. Research using these drift data should consider integrating these biases into their analyses, particularly where absolute ground speed or direction is necessary. Further investigation is required into the sources of error, particularly in under-examined areas without in situ data.
\end{abstract}

\section{Introduction}

Many research fields increasingly depend on remote sensing to collect environmental data. The raw data from various remote sensing sources are often combined using modelling and interpolation techniques to create an accessible gridded product (Reichle, 2008)- for example, the Hadley Centre Sea Ice and Sea Surface Temperature dataset, which combines data from numerous sources including active and passive satellite sensors, ice charts, and historic records (Titchner and Rayner, 2014). However, measurement errors and assimilation biases can lead to large inaccuracies (Reichle, 2008). If the degree of measurement error is greater than the variability of the system being modelled, it could lead to spurious results (Auger-Méthé et al., 2016b). Quantifying error in remotely sensed data can be used to improve these data products (Cressie et al., 2009) and is important for data assimilation and the development of new products (Meier et al., 2000; Sumata et al., 2014, 2015a). However, assessing these errors is challenging, particularly in remote areas that are difficult to ground truth.

Sea ice studies often rely on remotely sensed data due to the remote, vast, and dynamic nature of the environment. Sea ice drift is a fundamental contributor to the dynamism of the Arctic ecosystem. Ice drift affects important thermodynamic processes through the formation of polynyas and leads (Marcq and Weiss, 2012), modulates ice deformation rates (Bouillon and Rampal, 2015; Rampal et al., 2009), and 
can determine spatial distribution and configuration of different ice ages and thicknesses (Hutchings and Rigor, 2012; Mahoney et al., 2019). It also drives the rate of sea ice export, which affects ice extent throughout the Arctic (Rampal et al., 2009). Therefore, ice drift is often considered in models of ice cover characteristics, overall sea ice mass throughout the Arctic, and global climate patterns (Hunke et al., 2010; Kimura and Wakatsuchi, 2000; Kwok et al., 2013). In addition to geographic and environmental studies, ice drift has received increased attention in ecological research. Ice drift influences the distribution and biomass of plankton (Hop and Pavlova, 2008; Kohlbach et al., 2017; Onodera et al., 2015; Thorpe et al., 2007), as well as polar bear (Ursus maritimus) behaviour and energetics (Auger-Méthé et al., 2016a; Durner et al., 2017; Mauritzen et al., 2003). In addition to its effects on geophysics and wildlife, ice drift is also important in describing transport of microplastics in the Arctic (Peeken et al., 2018). Given its broad application, the accuracy of ice drift data is critical when drawing geophysical and ecological conclusions.

Several sources of ice drift data are available at variable spatiotemporal resolutions (Sumata et al., 2014). Although the data and models used vary between ice products, ice drift estimates are generally estimated from combinations of buoy data, weather forecast models, and satellite measurements. These data sources vary in coverage, resolution, accuracy, and sensitivity to environmental/meteorological conditions and, therefore, result in products with variable sources of error (Mahoney et al., 2019; Sumata et al., 2014). In this paper, we sought to quantify these errors in a widely employed sea ice drift data product produced by the National Snow and Ice Data Center (NSIDC; Boulder, CO): Polar Pathfinder Daily $25 \mathrm{~km}$ EASE-Grid Sea Ice Motion Vectors (hereafter, NSIDC drift; Tschudi et al., 2019, 2020). NSIDC drift estimates are produced by assimilating drift obtained from several satellite-based sensors, buoys, and modelled wind fields, providing among the most extensive, high-resolution, and complete spatial coverage. In addition, the NSIDC drift product has the longest temporal coverage of any sea ice drift products extending from 1978 to the present (Tschudi et al., 2020).

Although research has examined the accuracy of older versions of NSIDC drift (e.g., Ruslan, 2018; Schwegmann et al., 2011; Sumata et al., 2014, 2015b), the latest major release (version 4.0) has yet to be externally evaluated. The NSIDC drift model integrates the movement of buoys from the International Arctic Buoy Program (IABP; http: //iabp.apl.washington.edu/, last access: 10 June 2020), and the buoys are the highest weighted input source driving the NSIDC model (Sumata et al., 2015a). Regions without such in situ measurements are more susceptible to bias (Mahoney et al., 2019; Sumata et al., 2015a; Tschudi et al., 2020) and are therefore particularly important to evaluate.

There are two types of data that can be used to cross validate ice drift: (1) other telemetry-based estimators includ- ing moored Doppler-based velocity measures and other highresolution satellites (e.g., Advanced Very High Resolution Radiometer, AVHRR; or synthetic aperture radar, SAR), and (2) in situ drifters, including buoys, ships, and manned stations (Lavergne et al., 2016). Other satellite-based estimates are associated with their own estimation errors, and Dopplerbased validation represents only errors in the area in which they are moored (Rozman et al., 2011). Some studies used in situ drifters (e.g., drifting research stations or buoys) as reference data; however, they are consequently limited in spatial extent (Hwang, 2013; Rozman et al., 2011; Tschudi et al., 2010). Since there are few sources of in situ sea ice drift data, at least one study quantifying NSIDC drift accuracy used the same IABP data that are integrated into the NSIDC model for validation, which may underestimate bias (e.g., Sumata et al., 2014). Further, IABP buoys have historically used ARGOS location estimates, which have spatial errors up to tens of kilometres and may be unsuitable for validation of drift during the periods/areas in which they were deployed (Hwang, 2013).

In this paper, we evaluate the bias and precision (hereafter collectively referred to as accuracy) of NSIDC drift data in Hudson Bay using an opportunistic and independent source of sea ice drift validation data. We compared modelled NSIDC drift to drifting GPS collars that were originally deployed on polar bears but dropped onto sea ice. There has been no study of the accuracy of any sea ice drift model in Hudson Bay. In addition, the bay does not have any IABP buoys, which drive the NSIDC model and its performance. Our objectives were to quantify drift accuracy within three domains: drift speed, drift direction, and the orthogonal (horizontal, $u$; and vertical, $v$ ) components of the drift vectors. We also explored whether accuracy varied with the underlying drift speed, across months, or across years.

\section{Methods}

We fitted polar bears in western Hudson Bay, Canada, with satellite-linked GPS collars (Telonics ${ }^{\circledR}$, Mesa, Arizona) in August and September of 2004-2015 (Fig. 1). Procedures for animal capture and handling are described by Stirling et al. (1989) and were approved annually by the University of Alberta Animal Care and Use Committee for Biosciences and by the Environment and Climate Change Canada Western and Northern Region Animal Care Committee. Protocols were in accordance with the Canadian Council on Animal Care. Collars were programmed to obtain GPS fixes every $4 \mathrm{~h}$. The locations obtained have a high accuracy, with errors < $31 \mathrm{~m}$ (D'Eon et al., 2002). Although deployed with the purpose of studying polar bear behaviour and space use, some collars may slip off the bears, they may release early due to premature failure of the release mechanism, or the bear may die while the collars continue to transmit locations. In these instances, the observed displacement of the collars 


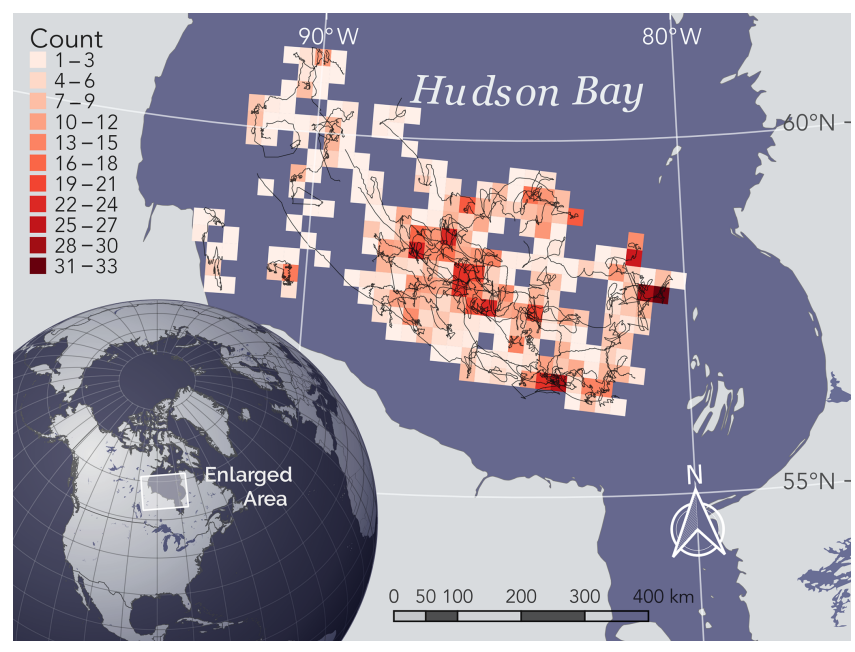

Figure 1. Hudson Bay study area (enlarged), tracks of dropped collars (black lines), and count of drift vectors (shaded cells, projected in $25 \mathrm{~km}$ EASE-Grid North, EPSG: 3408). World borders dataset obtained from Sandvik (2009).

represents the motion of sea ice. We identified drifting collars either through activity sensors in the collars or by manually comparing the observed collar displacement with sea ice satellite imagery (Appendix A). To verify that manually identified drifting collars were passively drifting and not on active bears, we compared accuracy metrics for speed, direction, and $u$ and $v$ (relative to the NSIDC drift projection, EPSG: 3408) among activity sensor collars, manually identified passive collars, and collars on active bears. Detailed methods and results of this comparison are presented in the Appendix B.

We used the motion of the identified drifting collars (following date of inactivity/drop off; hereafter simply collars) to quantify the accuracy and precision of NSIDC drift data. The NSIDC product provides daily estimates of sea ice drift derived from buoy data; National Centers for Environmental Prediction and National Center for Atmospheric Research reanalysis wind vectors; and several satellite sensors including AVHRR, the Advanced Microwave Scanning Radiometer for the Earth Observing System (AMSR-E), Scanning Multichannel Microwave Radiometer (SMMR), and the Special Sensor Microwave Imager/Sounder (SSMI/S; Tschudi et al., 2019, 2020). To match the NSIDC product, collar locations were projected into the $25 \mathrm{~km}$ EASE-Grid North (EPSG: 3408) projection used by NSIDC. NSIDC represents drift as movement between 12:00 UTC of subsequent days. To match the NSIDC temporal resolution, we subsampled the collar locations to a $24 \mathrm{~h}$ resolution by retaining locations from 13:00 UTC, the closest collar location to 12:00 UTC. Next, we calculated drift vectors/components (i.e., speed, direction, $u$, and $v$ ) and then removed any vectors from locations $>24 \mathrm{~h}$ apart. Next, we interpolated the NSIDC drift to the first location of each collar drift vector using inverse dis- tance weight (inverse distance power set to three and maximum distance of $50 \mathrm{~km}$ ) to match the fix location.

The summary statistics chosen to quantify drift accuracy can lead to incomplete or spurious conclusions (Volkov et al., 2017). For example, root mean square and standard errors convey the magnitude of the error but not the direction. Correlation coefficients between model and reference data describe model precision but not accuracy. Some studies investigated the accuracy of the orthogonal components of drift (i.e., $u$ and $v$ ) individually; however, this does not convey the accuracy in speed and direction, which are emergent properties of both components. For example, if the biases of the orthogonal components are equal and scale proportionally, then direction estimates remain accurate. Conversely, if the biases are negatively correlated, they may partially cancel and result in speed estimates more accurate than appear when examining the drift components independently. Thus, in addition to the orthogonal $u$ and $v$ components of drift, we also quantified the accuracy of drift speed and direction.

We tested the following five key questions. (1) Are the estimated model speeds significantly different from the collar speeds? (2) Is the relative speed accuracy dependant on the underlying drift speed being estimated? (3) Are the estimated model directions significantly different from the collar directions? (4) Is the direction accuracy dependant on the underlying drift speed? And (5) do the relationships between the model $u(v)$ and collar $u(v)$ components diverge significantly from each other? Because the data are spatiotemporally autocorrelated, with subsequent days having similar drift speeds and different collars sampling different regions of Hudson Bay, we could not use a simple paired $t$ test for the absolute speed bias (1). Instead, we used an intercept-only generalized linear mixed model (GLMM; with a Gaussian error distribution) with absolute speed bias $\left(\right.$ Speed $_{\text {NSIDC }}-$ Speed $\left._{\text {collar }}\right)$ as the response, wherein a significant intercept represents a significant difference between the model and the collar speeds. To account for repeat sampling from different collars representing different regions, collar identity was used as a random effect. To account for temporal autocorrelation, we fit the model with a first-order autoregressive error process (AR1). For speed-dependant accuracy of model speed (2), we defined relative speed accuracy as the quotient of NSIDC drift speed over collar speed, $\frac{\text { Speed }_{\text {NSIDC }}}{\text { Speed }_{\text {collar }} \text {, with values }}>1$ representing overestimation and values $<1$ representing underestimation. This relative speed accuracy was modelled as a function of $\log \left(\operatorname{Speed}_{\text {collar }}\right)$ using GLMMs with gamma error distribution and a log-link function. We log transformed Speed $_{\text {collar }}$ because it is zero bound and the relative difference in speed (and thus its relative effect on model accuracy) decays exponentially with increasing values. We used the same random effect and AR1 structure as in (1). We assessed the accuracy of model direction, Direction NSIDC $_{-}$Direction $_{\text {collar, }}$, (3) using a WatsonWilliams test for homogeneity of means for circular data. Al- 


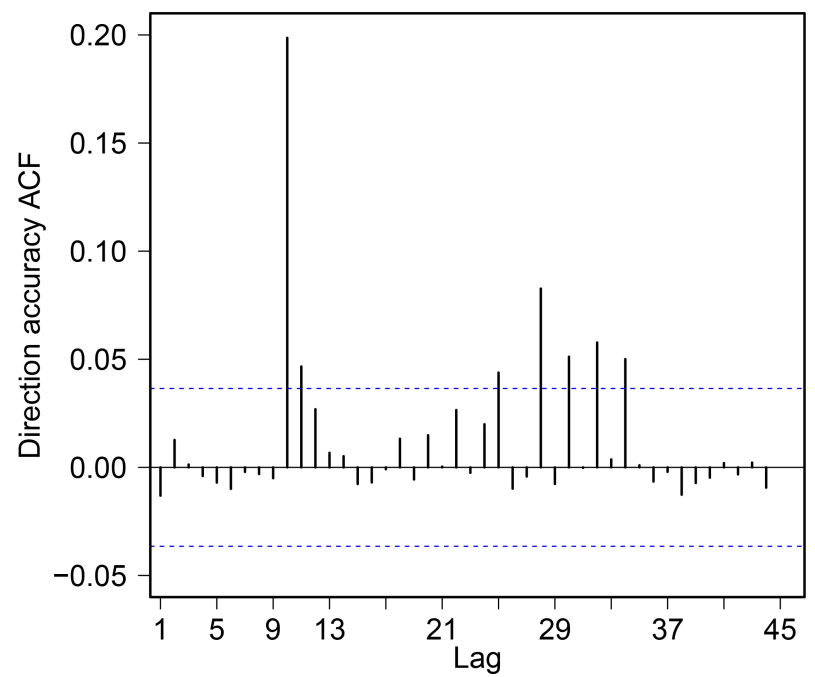

Figure 2. Autocorrelation function (ACF) for NSIDC linearized direction accuracy, $\tan \left(\mid\right.$ Direction $_{\text {NSIDC }}-$ Direction $\left._{\text {collar }} \mid / 2\right)$. Blue lines correspond to the $95 \%$ confidence interval (CI) limits that represent significant autocorrelation.

though this test does not incorporate autocorrelation, the absolute direction accuracy did not exhibit temporal autocorrelation (Fig. 2). For the speed-specific direction accuracy (4), we defined relative direction accuracy as the linearized absolute difference in direction, $\tan \left(\frac{\mid \text { Direction }_{\text {NSIDC }}-\text { Direction }_{\text {collarl }} \mid}{2}\right)$, where 0 represents model unanimity and departure from 0 represents increasing error. This relative direction accuracy was modelled as a function of $\log \left(\operatorname{Speed}_{\text {collar }}\right)$ using the same GLMM procedures used for testing speed-specific relative speed accuracy (2). Any differences in speed or direction between the NSIDC and collar drift ultimately emerge from the estimated $u$ and $v$ components of sea ice drift. We assessed the relationship between the orthogonal components of NSIDC and collar drift (5) using GLMM (with a Gaussian error distribution), with model $u(v)$ modelled as functions of collar $u(v)$, and the same random effect and AR1 structure as in (1), (2), and (4). All GLMMs were fit using penalized quasi-likelihood (GLMM $\mathrm{PQL}$; Breslow and Clayton, 1993) using the glmmPQL function of the MASS package (Venables and Ripley, 2002). Using GLMMPQL enabled us to meet all our model criteria: non-linear models with random effects and an autoregressive structure. As a broad metric of goodness of fit, we used the GLMM $\mathrm{PQL}^{2}$ metric developed by Jaeger et al. (2017) using the r2beta function in the $\mathrm{r} 2 \mathrm{glmm}$ package. All data processing and analyses were conducted in $\mathrm{R}$ version 3.6.1 (R Core Team, 2019).

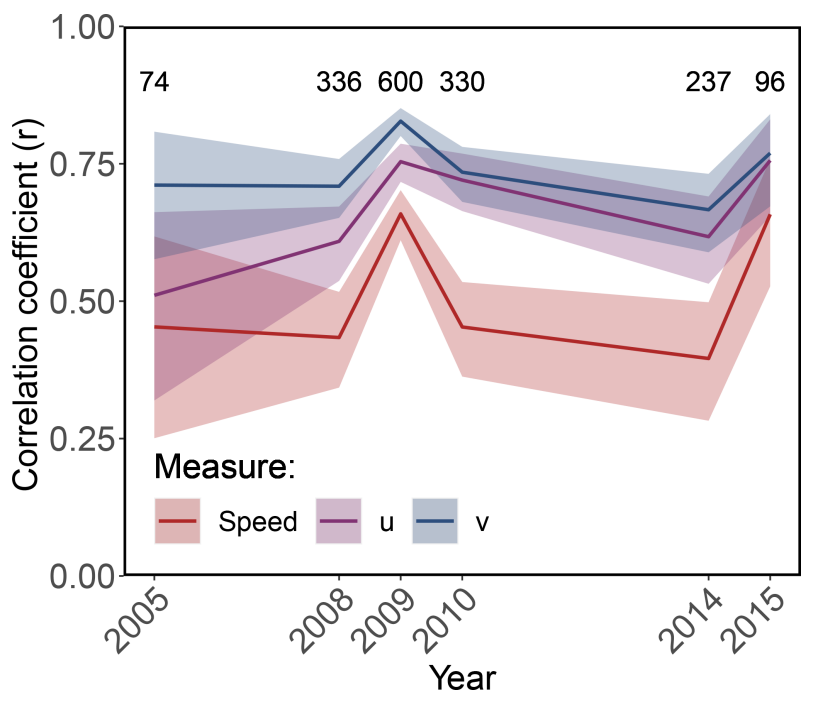

Figure 3. Interannual variation in correlation coefficients $(r)$ between NSIDC drift and collar drift speed (red line), $u$ component (purple line), and $v$ component (blue line). Shaded areas represent the $95 \%$ CI of the correlation coefficient. Numbers at the top represent the number of drift vectors compared in each year. Year 2013 is excluded due to insufficient data $(n=4)$.

\section{Results}

We identified 20 drifting collars with locations from December-July of 2005-2015 (Figs. 1 and 3), with a mean of $520 \pm 358$ GPS fixes per collar (total $=10409)$. The largest number of identified collars in 1 year was in $2009(n=6)$. The motion for these six collars is depicted in the Video supplement (https://doi.org/10.5446/45186, Togunov et al., 2020), which depicts the large degree of concurrence of drift vectors across large spatial extent. After subsampling to a daily resolution, we analyzed 1677 collar drift vectors. The number of drift vectors ranged from 71 vectors in July to 304 vectors in March (mean $=210 \pm 83$ vectors; Fig. 4).

\subsection{Accuracy of NSIDC drift speed}

Mean NSIDC drift speed was $5.8 \pm 4.5 \mathrm{kmd}^{-1}$ while mean collar speed was $8.4 \pm 7.1 \mathrm{~km} \mathrm{~d}^{-1}$; the difference in

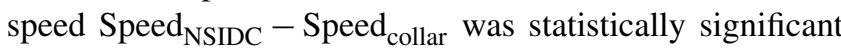
$\left(\mathrm{GLMM}_{\mathrm{PQL}}\right.$ : intercept $\pm 95 \%$ confidence interval $(\mathrm{CI})=$ $-3.0 \pm 1.2 \mathrm{~km} \mathrm{~d}^{-1}$, degrees of freedom $(\mathrm{df})=1657, t$ value $=-4.8, p$ value $<0.0001$; Fig. 5). NSIDC drift speeds were slower than collar drift speeds in $63.1 \%$ of the vectors, and only $10.4 \%$ of NSIDC drift speeds were within $\pm 10 \%$ of collar drift speeds (Fig. 5a). The discrepancy in drift speed was more pronounced at higher collar drift speeds, with a significant relationship between the quotient $\left(\frac{\text { Speed }_{\text {NIIDC }}}{\text { Speed }_{\text {collar }}}\right)$ and collar speed $\left(G_{\text {GLMM }}\right.$ PQL slope $=-0.67, \mathrm{df}$ $=1656, t$ value $_{\text {slope }}=-38.80, p$ value $_{\text {slope }}<0.0001, R^{2}=$ 0.53 ; Fig. 5b). Collar drift speeds $<4.5 \mathrm{~km} \mathrm{~d}^{-1}$ were over- 


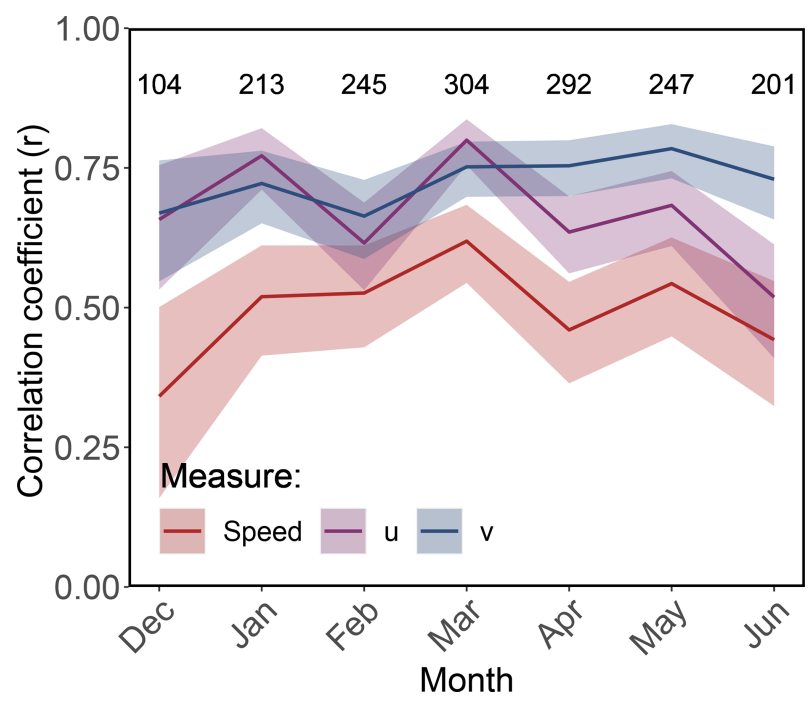

Figure 4. Intra-annual variation in correlation coefficients $(r)$ between NSIDC drift and collar drift speed (red line), $u$ component (purple line), and $v$ component (blue line). Shaded areas represent the $95 \%$ CI of the correlation coefficient. Numbers at the top represent the number of drift vectors compared in each month. July is excluded due to insufficient data $(n=71)$.

estimated by a median of $42 \%$, speeds between 4.5 and $9.0 \mathrm{~km} \mathrm{~d}^{-1}$ were underestimated by a median of $26 \%$, and speeds $>9.0 \mathrm{~km} \mathrm{~d}^{-1}$ were underestimated by a median of $51 \%$ (Fig. 5). There was intra-annual and inter-annual variation (based on $95 \%$ CIs) in the correlation of NSIDC drift speeds and collar drift speeds; however, there was no apparent pattern (Figs. 3 and 4).

\subsection{Accuracy of NSIDC drift direction}

NSIDC drift directions were on average $2.6^{\circ} \pm 53.9^{\circ}$ left relative to the collar drift direction, although the mean difference was not significantly different from $0^{\circ}$ (WatsonWilliams test: $\mathrm{df}_{1}=1, \mathrm{df}_{2}=1676, F$ value $=0.003, p$ value $=0.95$; Figs. 6 and 7 ). Most $(71.3 \%)$ of the NSIDC drift directions were within $\pm 22.5^{\circ}$ of the collar drift directions (Fig. 7). NSIDC drift direction tended to be more accurate at higher collar drift speeds, with a significant relationship between relative direction accuracy and collar drift speeds $\left(\right.$ GLMM $_{\mathrm{PQL}}$ : slope $=-0.83, \mathrm{df}=1656, t$ value $_{\text {slope }}=$ $-7.52, p$ value $_{\text {slope }}<0.0001, R^{2}=0.03$; Fig. 7).

\subsection{Accuracy of orthogonal NSIDC drift components}

Mean collar drift $u$ component was $-0.9 \pm 7.7 \mathrm{~km} \mathrm{~d}^{-1}$ compared to $-0.7 \pm 4.3 \mathrm{~km} \mathrm{~d}^{-1}$ for NSIDC drift $u$ drift. Mean collar drift $v$ component was $-1.1 \pm 7.7 \mathrm{~km} \mathrm{~d}^{-1}$ compared to $-0.8 \pm 4.5 \mathrm{~km} \mathrm{~d}^{-1}$ for NSIDC drift $v$ component drift. NSIDC and collar drift components were significantly related in both the $u$ component $\left(\mathrm{GLMM}_{\mathrm{PQL}}\right.$ : slope $\pm 95 \%$ CI $=0.38 \pm 0.02, \mathrm{df}=1656, t$ value $_{\text {slope }}=$
37.58, $p$ value $_{\text {slope }}<0.0001, R^{2}=0.46$; Fig. 8) and the $v$ component $\left(\mathrm{GLMM}_{\mathrm{PQL}}\right.$ : slope $\pm 95 \% \mathrm{CI}=0.40 \pm 0.02 \mathrm{df}$ $=1656, t$ value $_{\text {slope }}=37.54, p$ value slope $<0.0001, R^{2}=$ 0.52; Fig. 8). Although the components of NSIDC drift and collar drift were significantly correlated, the slopes of the regression were significantly underestimated (indicated by the slope estimate and $95 \% \mathrm{CI}$ being $<1$ ).

\section{Discussion}

Using drifting collars as reference data for validation, we identified biases in the estimated speed and direction of the NSIDC sea ice drift model. NSIDC drift speeds tended to be underestimated, although drift direction was relatively accurate. This is due to the underestimation of $u$ and $v$ components, which showed a similar magnitude in their bias. The biases in speed and direction were related to the underlying drift speed as measured by the collars. NSIDC drift speeds tended to overestimate slow collar drift $\left(<4.5 \mathrm{~km} \mathrm{~h}^{-1}\right)$ and underestimate high collar drift $\left(>4.5 \mathrm{~km} \mathrm{~h}^{-1}\right)$. This pattern is likely an effect of estimating a zero-bound variable and is consistent with other satellite-based sea ice drift products (Johansson and Berg, 2016; Mahoney et al., 2019; Rozman et al., 2011; Sumata et al., 2014). As drift speeds approach $0 \mathrm{~km} \mathrm{~d}^{-1}$, the probability of overestimation approaches 1 , and as drift speeds increase, the range of values that are below the drift speed (i.e., underestimates) increases. Although the bias is mathematically inevitable to some degree, the magnitude of the bias is not fixed, and our results show that the error can be high, with drift speeds underestimated by a median of $22.9 \%\left(1.4 \mathrm{~km} \mathrm{~d}^{-1}\right)$. This is similar to the drift bias observed by Durner et al. (2017) in the Beaufort and Chukchi seas, wherein mean daily model speed was underestimated by a mean of $28.0 \%\left(2.25 \mathrm{~km} \mathrm{~d}^{-1}\right)$. These biases are small relative to the $25 \mathrm{~km}$ resolution of the satellite input data; however, in some analyses, the bias would compound over time. For example, cumulative/total daily drift calculated for 7 months (corresponding to the months in which we obtained drift data) would be underestimated by $>295 \mathrm{~km}$. Drift direction accuracy increased at higher collar drift speeds. This is probably because magnitude and uniformity of sea ice displacement increase with drift speed, and this is more likely to be detected by NSIDC's featurematching algorithm (based on maximum cross correlation; Tschudi et al., 2019).

Our estimates of drift speed bias are greater than estimated in studies of NSIDC and other drift products (Durner et al., 2017; Hwang, 2013; Johansson and Berg, 2016; Lavergne, 2016; Schwegmann et al., 2011; Sumata et al., 2014). However, the Hudson Bay system is different from areas where drift accuracy has been studied. First, Hudson Bay has a smaller area-to-shoreline ratio due to its smaller size compared to the rest of the Arctic Ocean (excluding the Canadian Arctic Archipelago), which confounds satellite and wind- 

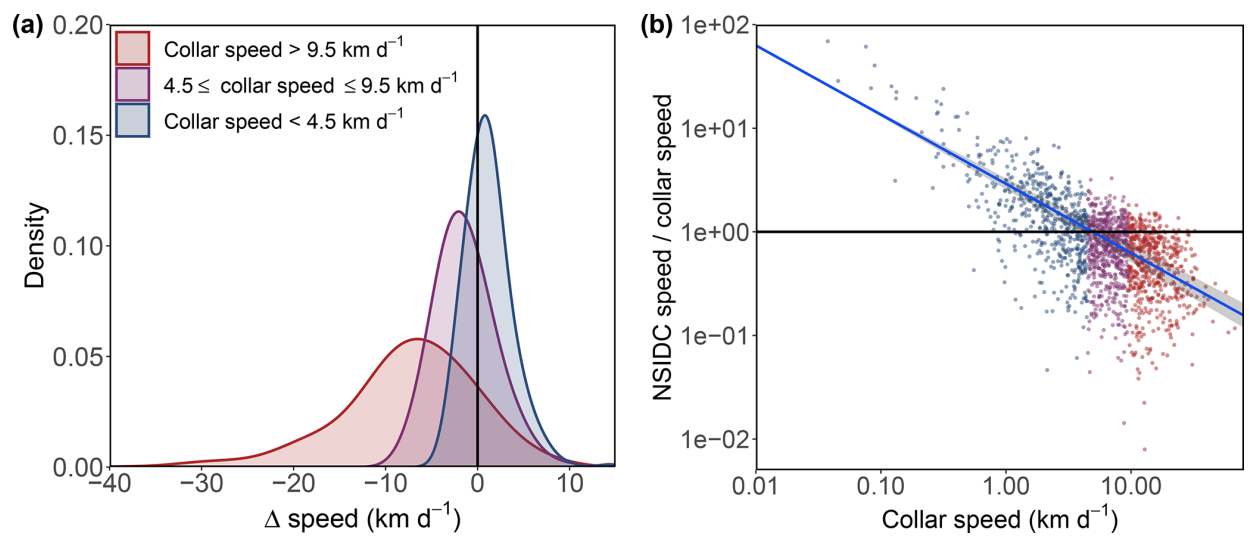

Figure 5. Accuracy of NSIDC drift speed represented by (a) a histogram and density plot of the absolute accuracy $\left(\operatorname{Speed}_{\text {NSIDC }}-\right.$ Speed $\left._{\text {collar }}\right)$

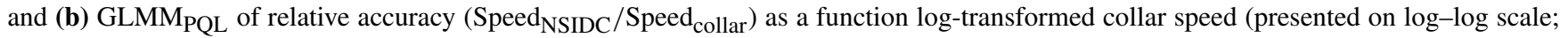

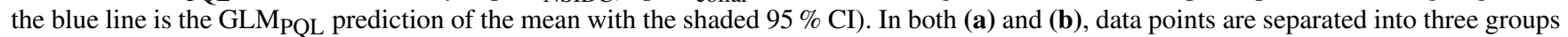
(red, purple, and blue) based on collar speed to convey speed-specific variability in accuracy. Black lines represent $1: 1$ unanimity between NSIDC and collar drift speeds.

(a)

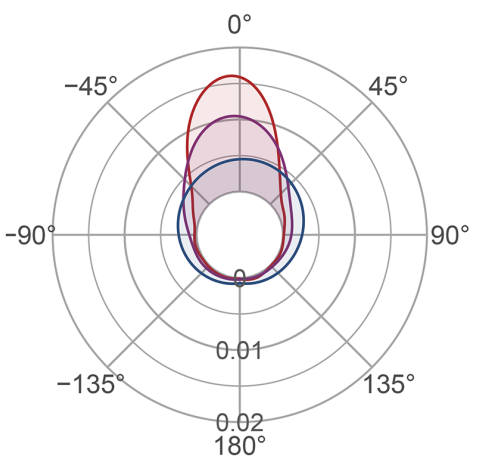

$\Delta$ Direction (density)

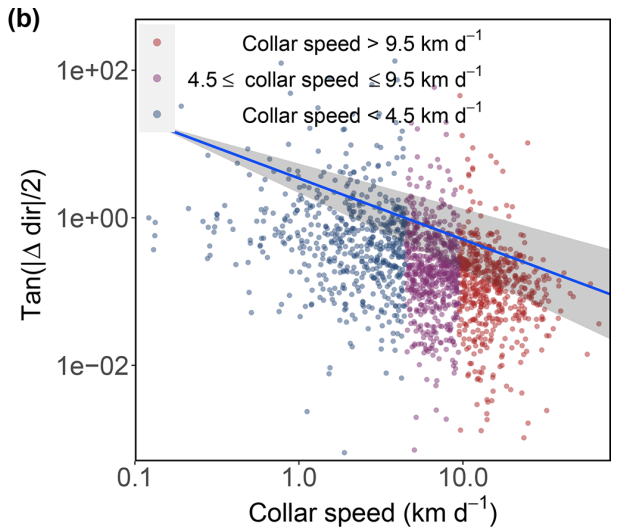

Figure 6. Accuracy of NSIDC drift direction represented by (a) a circular histogram and density plot of the absolute accuracy

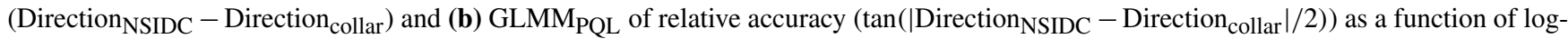
transformed collar speed (presented on a $\log -\log$ scale, with a zero value representing $1: 1$ unanimity); the blue line in (b) represents the

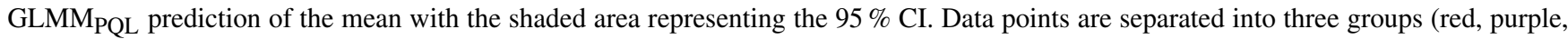
and blue) based on collar speed to convey speed-specific variability in accuracy.

based drift estimation (Thorndike and Colony, 1982; Tschudi et al., 2020). Satellite-based tracking relies on a featurematching algorithm and cannot resolve velocities near the shore (Heil et al., 2001; Meier et al., 2000; Tschudi et al., 2020). While currently NCEP wind is weighted half as much as buoy or satellite data, Tschudi et al. (2020) noted that wind-based estimates are comparable to satellite estimates and may need to be given a higher weight. Although giving wind estimate higher weight may improve drift estimates in Hudson Bay, it may still result in speed underestimation. Wind-based drift estimates assume a $20^{\circ}$ relationship with direction and a $1 \%$ relationship with speed, although this speed relationship may actually be higher (up to $3 \%$; Bai et al., 2015; Rabinovich et al., 2007). The effect of wind on drift also varies depending on proximity to shore and the orienta- tion of wind relative to the shoreline. Near the coast, internal ice stress/forces can exceed those of wind and currents, with the effects extending up to $400 \mathrm{~km}$ (Fissel and Tang, 1991; Overland and Pease, 1988; Rabinovich et al., 2007; Thorndike and Colony, 1982). More complex regressionbased models that account for proximity and orientation of shorelines have been shown to improve wind-based drift estimates (Rabinovich et al., 2007). Second, the bay is a seasonal system, completely melting in summer and reaching nearly $100 \%$ cover in winter (Danielson, 1971; Saucier et al., 2004; Stewart and Barber, 2010). Consequently, sea ice in Hudson Bay lacks multi-year ice, and the ice is younger and generally thinner, with extensive periods of low concentration, factors which both decrease accuracy of modelled ice drift (Durner et al., 2017; Mahoney et al., 2019; Sumata et al., 2014). At 


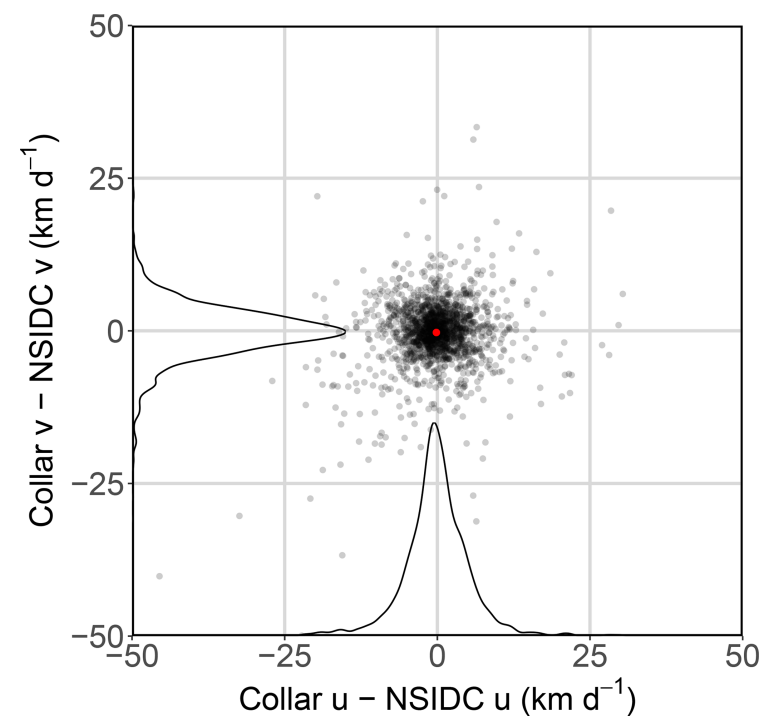

Figure 7. Difference between collar drift and NSIDC drift for the $u$ ( $x$ axis) and $v$ ( $y$ axis) components. Curves represent density of differences, and the red dot represents the mean difference of $u$ and $v$ components.

low ice concentrations, satellites sensors are more likely not to detect sea ice (Castro de la Guardia et al., 2017; Tivy et al., 2011). The formation of new sea ice during freeze-up and the melt ponds that form during break-up both confound estimation of drift (Meier et al., 2000; Tschudi et al., 2020; Willmes et al., 2009). Third, there are no IABP buoys in Hudson Bay to contribute data to the NSIDC drift model, another factor associated with poorer model performance (Mahoney et al., 2019; Tschudi et al., 2020). Earlier versions of NSIDC drift products (see Tschudi et al., 2016) effectively limited the influence of buoys to $\sim 350 \mathrm{~km}$, which introduced artefacts around buoy locations (Szanyi et al., 2016). Changes to the algorithm in version 4 of NSIDC drift eliminated the artefacts and increased accuracy within the Arctic Ocean (Tschudi et al., 2020); however, these changes would not have improved drift estimates in regions without buoy data, including Hudson Bay. Last, the EASE-Grid projection is polar azimuthal and induces meridional compression and zonal stretching, which further biases drift estimation. The effect of this distortion is that north-south (east-west) drift is more likely to be underestimated (overestimated), and direction estimates will be biased toward the east-west axis. This bias is amplified as you approach the equatorial limits of the dataset and is particularly important if groundspeed is required. Hudson Bay is the furthest body of water from the poles where NSIDC drift is estimated and would therefore experience the greatest bias due to projection. In summary, our observed speed underestimation may be explained by the challenging topography of Hudson Bay for satellite and wind-based drift estimates, underestimation of wind's impact on ice motion, small weight given to the wind input data, lack of buoy data, and projection biases.

A common limitation of these types of studies is the reliance on interpolation. Bilinear, or inverse-distanceweighted, interpolation yields estimates that tend towards the mean and precludes obtaining outermost estimates (Schwegmann et al., 2011). In addition, interpolation within skewed distributions is likely to yield spurious estimates. For example, in right-skewed datasets (e.g., zero-bound drift speed), outliers are more likely greater than the mean, and inversedistance averaging is more likely to be an overestimate. Nevertheless, there is no reason to believe these biases would be greater than those of other sea ice drift validation studies that used linear interpolation to match satellite with in situ-based estimates (Lavergne, 2016; Schwegmann et al., 2011).

The drift biases we report are limited by availability of telemetry collar data, and we cannot definitively extrapolate our accuracy estimates beyond this spatiotemporal extent. Nevertheless, many of these biases have been reported in research of NSIDC and other satellite-based sea ice drift estimates (Heil et al., 2001; Karlsson, 2016; Lavergne, 2016; Linow et al., 2015; Rozman et al., 2011; Schwegmann et al., 2011; Sumata et al., 2014, 2015b, 2015a; Szanyi et al., 2016). Areas with similar characteristics to Hudson Bay may show similar biases in the estimated speed and direction of drift. This includes other seasonal systems (e.g., Baffin Bay) and those with slower drift (e.g., Kara and Laptev seas) or without IABP buoys (see IABP, 2020, and Rampal et al., 2009, for coverage). Further, we observed the relative degree of bias increases with speed. If such scaling in bias exists in other areas, then the magnitude of underestimation may be greater in areas with faster speeds (e.g., Chukchi Sea).

Assuming the overall NSIDC drift accuracy is consistent over time, these data are likely well suited for addressing questions where the relative speed or direction are sufficient, for example longitudinal analyses such as climate-induced changes in drift speed (e.g., Kwok et al., 2013; Klappstein et al., 2020). Still, a large error may obscure underlying trends. We suggest cautious application of the NSIDC drift data where the absolute speed or direction is critical - for example, calculation of animal energetics (e.g., Durner et al., 2017; Klappstein et al., 2020), home ranges (e.g., AugerMéthé et al., 2016a), voluntary movement (e.g., Togunov et al., 2017, 2018), and predicting/retrodicting distribution of drifting matter (Kohlbach et al., 2017; Peeken et al., 2018; Thorpe et al., 2007; Tschudi et al., 2010). The degree of error/bias that is permissible is research specific. Generally, to be able to correctly account for measurement error, it has to be smaller than the natural stochasticity of the system being studied (Auger-Méthé et al., 2016b). Particular attention to error/bias should be given in regions without IABP buoy data or where bias is unquantified. 
(a)

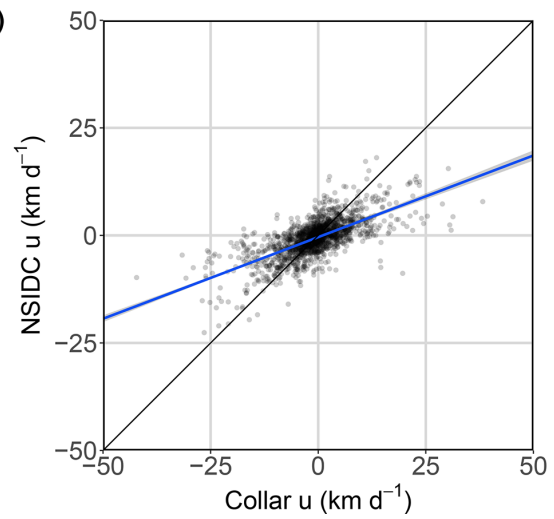

(b)

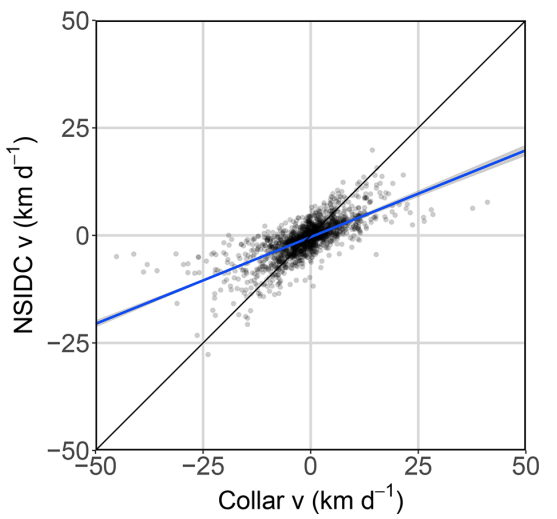

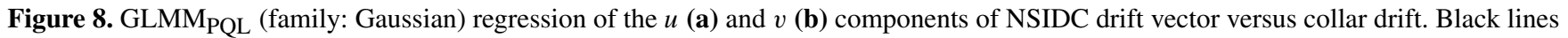
represent a $1: 1$ relationship between NSIDC and collar drift components; the blue lines represent the lines of best fit with the shaded areas representing the $95 \% \mathrm{CI}$ of the mean.

\section{Conclusions}

This study provides the first error estimates of any sea ice drift model in Hudson Bay. Using passively drifting telemetry collars, we quantified the accuracy and precision of Polar Pathfinder Daily $25 \mathrm{~km}$ EASE-Grid Sea Ice Motion Vectors, Version 4. Both $u$ and $v$ components of NSIDC drift along with the resultant speed tended to systematically underestimate true drift speed, a pattern exacerbated at higher speeds. The direction showed no systematic bias; however, directional precision decreased at lower speeds. We suggest that any research requiring absolute values for drift speed/direction should account for error/bias of drift in the study design and/or test the sensitivity of the results to these biases (Cressie et al., 2009).

Although our collar GPS data were collected with the intent of studying polar bear ecology, we believe it and other forms of animal-borne telemetry can be of great utility in advancing environmental modelling. For example, polar bear telemetry has been used to validate sea ice drift in the Beaufort and Chukchi seas (Durner et al., 2017; Tschudi et al., 2010) and to assess accuracy of sea ice concentration data (Castro de la Guardia et al., 2017), and seabird tracking has been used to estimate ocean currents and wind velocities (Goto et al., 2017; Yoda et al., 2014; Yonehara et al., 2016). In addition to being useful for model validation, these types of data can be incorporated into environmental models as additional data streams, providing insight into areas that are more difficult to measure (Harcourt et al., 2019; Miyazawa et al., 2015). To help improve modelled drift data, we have made the position data of our drifting collars public https://doi.org/10.7939/dvn/kuiz7g (Derocher, 2020). The data can also be used to identify error/bias associated with different locations, periods, or environmental conditions (e.g., ice thickness, ice concentration, and cloud cover) in which models can be improved (e.g., Miyazawa et al., 2015). Our study provides evidence of modelled ice drift bias in
Hudson Bay, where a lack of Arctic buoys makes this type of study difficult. Ultimately, these findings (in combination with our public dataset and that of other drifting tag data; Durner et al., 2017; Øigård et al., 2010; Vacquie-Garcia et al., 2017) can be a good resource for quantifying and validating the accuracy of other and/or future ice drift products. 


\section{Appendix A: Drifting collar identification}

Collars deployed since 2011 were equipped with activity sensors that are triggered following an extended period of inactivity. These collars were considered passively drifting if the activity sensor turned on and stayed until the end of transmissions. Collars deployed before 2011 had to be identified manually in two stages.

First, GPS location data were annotated with sea ice motion vectors from NSIDC's Polar Pathfinder Daily $25 \mathrm{~km}$ EASE-Grid Sea Ice Motion Vectors, Version 3 (http://nsidc. org/data/nsidc-0116, last access: 10 June 2020). Daily drift estimates were spatiotemporally interpolated to match the location and time of GPS fixes - it was assumed that the ice motion data reflected average drift at noon of each day. For all $4 \mathrm{~h}$ GPS fixes, voluntary bear movement was estimated by subtracting the component of ice drift from the GPS displacement. This estimate of voluntary movement was plotted against time for each collar. Collars were suspected to be drifting if there was a sudden and sustained drop in movement speed (e.g., Fig. A1 versus Fig. A2). To confirm that the collars are indeed drifting, the displacement of these suspect collars had to be confirmed to reflect the actual sea ice drift.

Actual sea ice drift was derived from NASA's Earth Observing System Data and Information System (EOSDIS) satellite imagery (https://earthdata.nasa.gov/about, last access: 10 June 2020). First, the projection and scale of EOSDIS and collar locations had to be matched. The EOSDIS Worldview web interface (https://worldview.earthdata.nasa. gov/, last access: 10 June 2020) projection was set to "Arctic" (WGS 84/NSIDC Sea Ice Polar Stereographic North projection; EPSG: 3413 ), rotated $-69^{\circ}$, and maximally zoomed in. Collar locations were plotted in QGIS version 2.16.3; the projection was matched to EOSDIS (EPSG: 3413) and scaled in QGIS to $1: 480000$ (though the realized scale was $\sim 1: 1330000$ on the $13.3 \mathrm{in}$. computer at a $2560 \times 1600$ resolution).

Next, sea ice drift was estimated at a subset of locations for each suspected drifting collar using the following procedure. First, the view in QGIS was centred on GPS locations of a probably drifting collar where ice drift would be approximated, and the view in EOSDIS Worldview was matched. Second, we identified periods where the satellite imagery was relatively unobscured by clouds for at least $2 \mathrm{~d}$ and visually tracking ice floes would be possible. Third, a collar location representing the first location of a displacement vector (hereafter, first-day collar location) was marked using the screen annotation software AnnotatePro (https://web.archive.org/web/20190701171427/http: //www.annotatepro.com:80/, last access: 31 July 2018). Fourth, we identified unique sea ice features that could be tracked over both days. Unique ice features were mainly distinctive edges and corners of ice floes and fractures. Fifth, using AnnotatePro, we marked where an ice floe was on the day

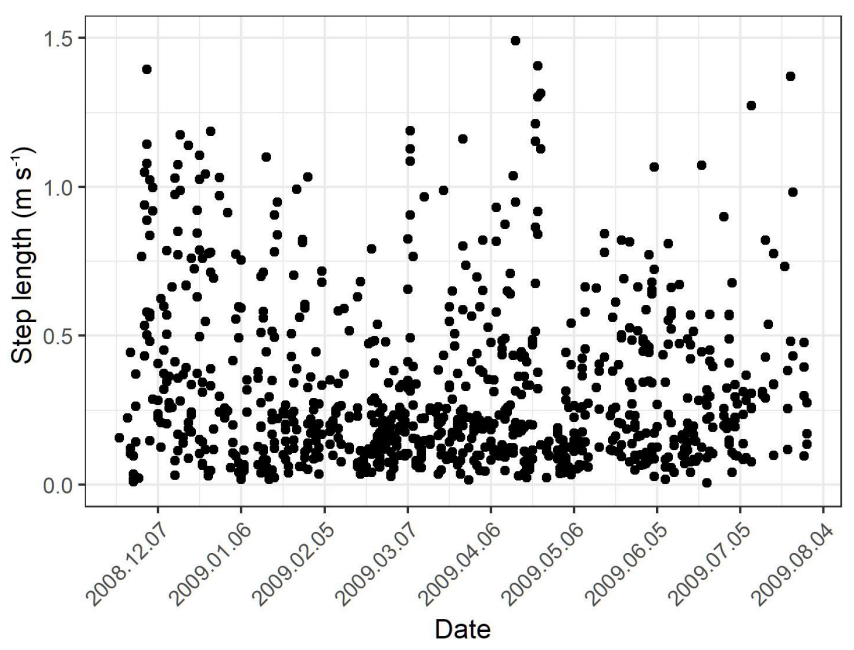

Figure A1. Example of estimated voluntary movement (step length in $\mathrm{m} \mathrm{s}^{-1}$ ) over time of a collar that is on a living bear.

of the collar location (hereafter, first-day ice location), and another point was marked where that same ice floe was on the following day (hereafter, second-day ice location). Sixth, both marks were selected using selection tool in AnnotatePro and moved such that the first-day ice location overlapped the first-day collar location. The second-day ice location represented where the collar would be located on the following day had the bear not moved. If the collar location was on an identified ice floe, only that floe was tracked. If the collar location was not on an identified floe, up to five additional floes around the collar location were identified and marked to attain an approximation of drift at the collar location. Seventh, the distance between second-day ice location and the secondday collar location was calculated using the "measure line" tool in QGIS. If several ice floes were marked and tracked, then the distance was measured from the second-day collar location to the approximate centre of all the second-day ice floe locations. At the operating scale being used, sea ice drift was relatively uniform, and there was very high consistency in drift among ice floes.

Collars were assumed to be passively drifting collars if the mean of at least four consecutive distance estimates (hereafter, distance estimate) was $<2 \mathrm{~km}$ (hereafter, distance threshold). At the maximum resolution permitted in EOSDIS, the $2 \mathrm{~km}$ distance threshold corresponded to $\sim 1.5 \mathrm{~mm}$ on screen. If the distance estimate was greater than the distance threshold, the collar was assumed to be on a live bear and not a drifting collar.

The EOSDIS imagery used was taken during daylight hours, so sea ice drift was estimated (as much as possible) for collar locations at 17:00 and 21:00 UTC, generally corresponding to midday in Hudson Bay. For each suspect drifting collar, sea ice drift was first estimated for the last days of collar locations; if the distance estimate was greater than the distance threshold (i.e., indicating a live bear), all prior 


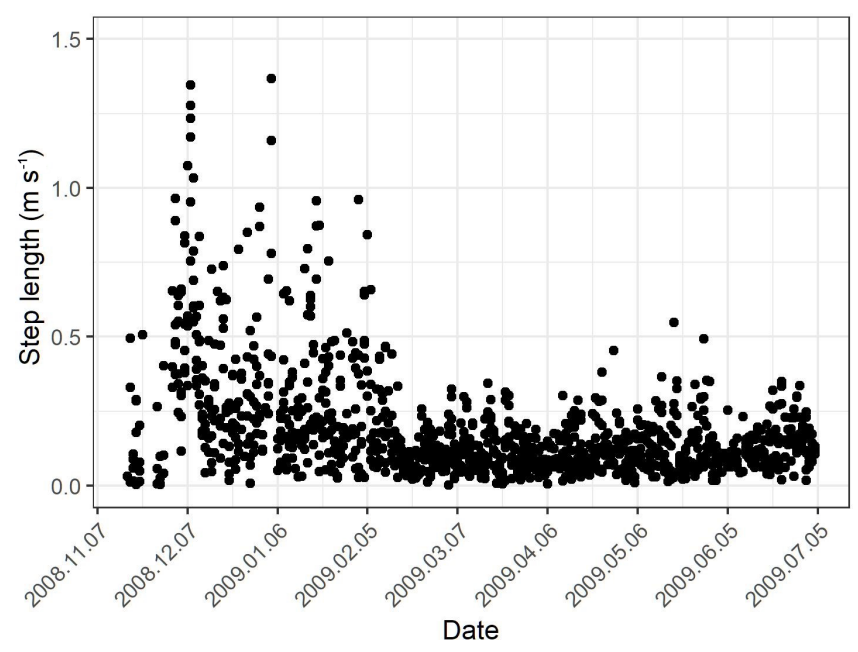

Figure A2. Example of estimated voluntary movement (step length in $\mathrm{m} \mathrm{s}^{-1}$ ) over time of a suspect passive collar.

locations must also have been on a live bear. If the distance estimates were less than the distance threshold the collar was assumed to be drifting, then drift was estimated iteratively $\sim 30 \mathrm{~d}$ into the past until the distance estimate indicated a live bear. Next, from the last date assumed to be drifting, sea ice drift was estimated iteratively $\sim 7 \mathrm{~d}$ into the past until the mean distance estimate indicated a live bear. Finally, from the last drifting collar date, we examined prior days sequentially until the distance estimate indicated a live bear. The following day was determined to be the date when the collar either dropped off the bear or the bear died.

For certain days, ice drift estimation was either very poor or not possible. Confounding factors included heavy cloud cover, blurry satellite imagery, small floes that were indistinguishable and not trackable (particularly common during freeze-up and break-up), consolidated ice with no trackable features, or days with extreme fracturing of ice floes beyond recognition. For these periods, certain modifications to the described protocols were permitted. For example, if cloudfree days were separated by up to two clouded days and sea ice drift could be estimated across that period, this was permitted. If many of the drift estimates were poor, researcher discretion was permitted to increase the drifting collar threshold from $2 \mathrm{~km}$. During periods with extensively poor ice drift estimation, if four sequential drift estimates spanned beyond a week, it was permitted to average fewer than four estimates.

\section{Appendix B: Drifting collar validation}

To lend additional support that manually identified collars were indeed not on active bears, we compared metrics of speed, direction, and $u$ and $v$ component accuracy calculated for manually identified collars, activity-sensor-identified collars, and active collars. First, we subset the active collars to a $24 \mathrm{~h}$ resolution by filtering only fixes obtained at 13:00 UTC. Second, we calculated the displacement vectors (speed, direction, and $u$ and $v$ components; calculated in the EASEGrid North projection, EPSG: 3408) between successive days, and then we filtered any vectors representing displacement over $>24 \mathrm{~h}$. Third, we subset the active collar vector data to the same number of locations as the drifting collars $(n=1677)$ and only in the years $(2005,2008-2010$, and 2013-2015) and months (December-June). These data were then compared to drifting collars identified manually and using the activity sensor.

The metrics of comparison were speed accuracy $\left(\right.$ Speed $_{\text {NSIDC }}-$ Speed $_{\text {collar }} ;$ Fig. Bla) and direction accuracy $\left(\right.$ Direction $_{\text {NSIDC }}-$ Direction $_{\text {collar }}$ Fig. B1b). We also tested the correlation in speed, direction, $u$ component, and $v$ component between NSIDC drift estimates and collar displacement vectors (Figs. B1c and B2). For speed, we calculated the Pearson correlation coefficient (Fig. B1c). For direction, we calculated the circular Pearson correlation coefficient $( \pm 95 \% \mathrm{CI})$ using the "cor.circular" function in the "circular" package in R. We used bootstrapping with 1000 replicates to calculate the $95 \%$ CI for this circular correlation (Fig. B1c). As an additional metric of directional accuracy, we estimated the concentration parameter (kappa $\pm 95 \% \mathrm{CI}$ ) on the difference between NSIDC drift and collar displacement vectors (Fig. B1c). Last, we fit a glmmPQL function (family: Gaussian) with the NSIDC drift $u$ and $v$ components as functions of $u$ and $v$ components of active, manually identified, and activity-sensor-identified collars (Fig. B1).

There were no significant differences between manually identified drifting collars $(n=13)$ and collars identified using activity sensor $(n=7)$ in accuracy metrics of speed, directional, or $u$ and $v$ components. However, both manually and activity-sensor-identified collars were consistently significantly different from collars on active bears with regard to the same accuracy metrics (Figs. B1 and B2). All results exhibit a significantly weaker relationship between NSIDC drift and displacement of active collars compared to either passively drifting collars.

The motion for six manually identified collars is depicted in the Video supplement (https://doi.org/10.5446/45186, Togunov et al., 2020). This video depicts the large degree of concurrence of drift vectors across a large spatial extent and further supports that the manually identified collars are in fact passively drifting. 


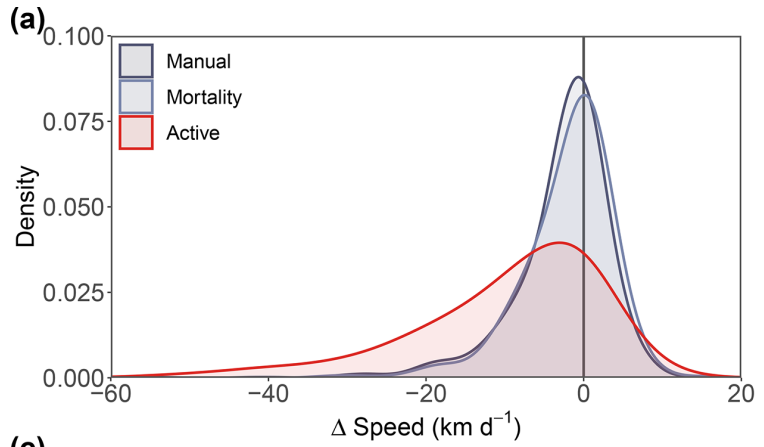

(b)
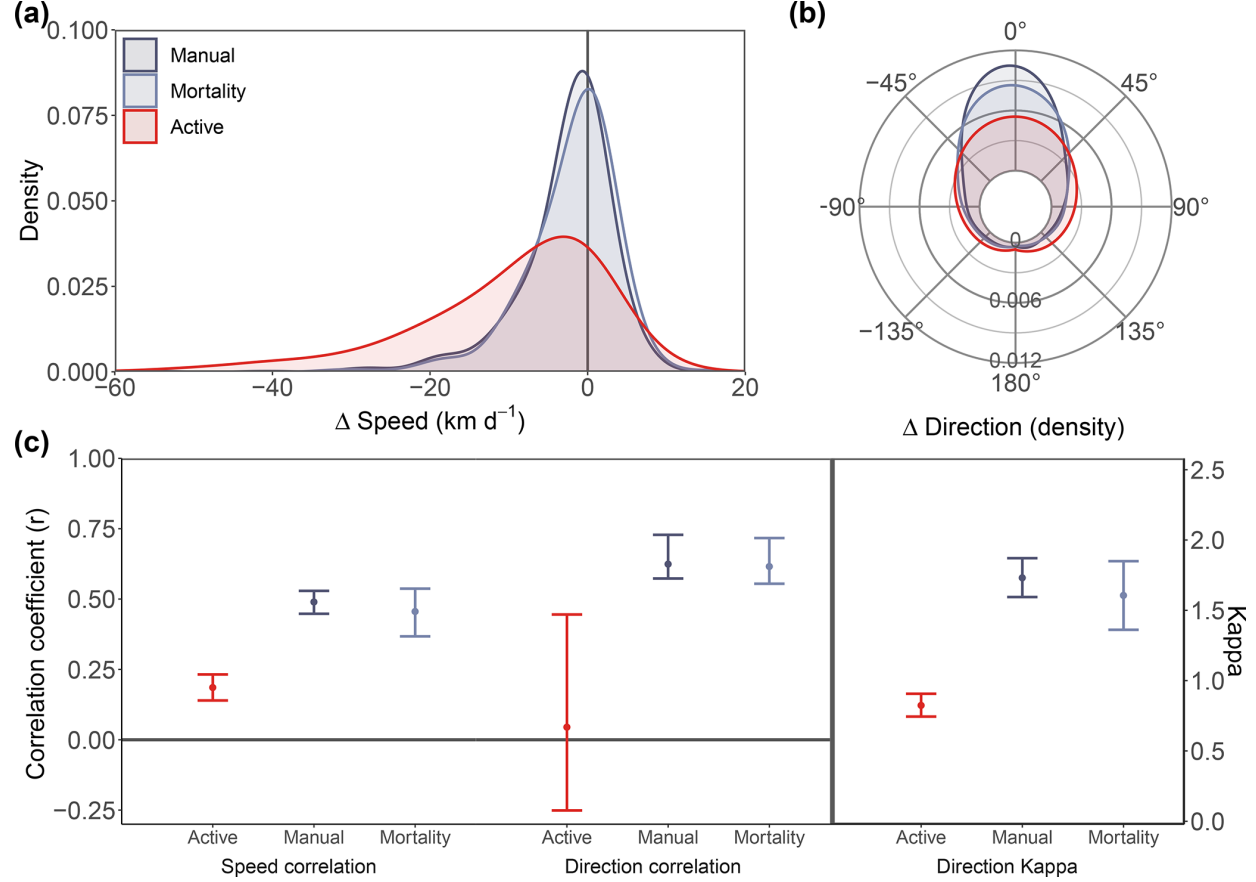

Figure B1. Comparison of speed and direction metrics of collars believed to be on active bears (red), manually identified drifting collars (dark blue), and activity-sensor-identified drifting collars (light blue). Metrics presented are density plot of the difference in speed, $\left(\right.$ Speed $_{\text {NSIDC }}-$ Speed $\left._{\text {collar }} ; \mathbf{a}\right)$, density plot of difference in direction (Direction NSIDC $_{-}$Direction $_{\text {collar }}$; b), Pearson's correlation coefficients of speed $\left(\right.$ Speed $_{\mathrm{NSIDC}} \sim \operatorname{Speed}_{\text {collar }} ; \mathbf{c}$, left) and direction $\left(\right.$ Direction $_{\mathrm{NSIDC}} \sim$ Direction $_{\text {collar }}$; $\mathbf{c}$, middle), and estimates of angular concentration (kappa) in the difference in direction (c, right). Error bars in (c) represent the $95 \%$ CI of the mean.

(a)

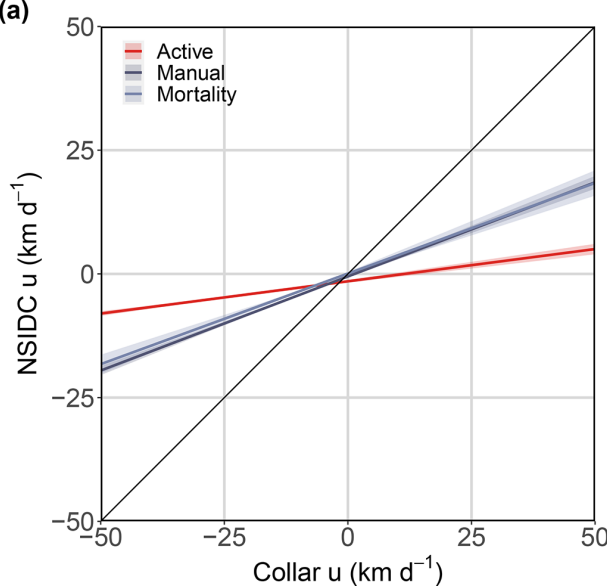

(b)

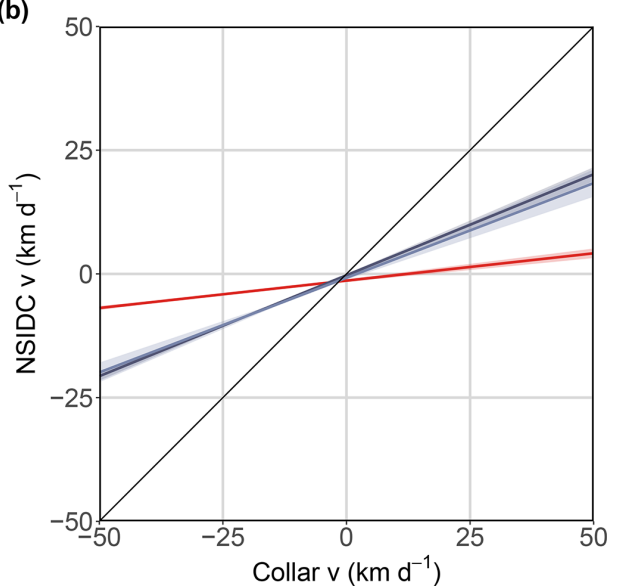

Figure B2. GLMM $\mathrm{PQL}_{\mathrm{L}}$ regression of the $u$ (a) and $v$ (b) components of the NSIDC drift vector versus collar drift among collars believed to be on active bears (red), manually identified drifting collars (dark blue), and activity-sensor-identified drifting collars (light blue). Black lines represent a 1:1 relationship between NSIDC and collar drift components; shaded areas represent the $95 \%$ CI of the mean. 
Data availability. The Polar Pathfinder Daily $25 \mathrm{~km}$ EASE-Grid Sea Ice Motion Vectors (version 4) dataset is available at https: //nsidc.org/data/nsidc-0116/versions/4 (Tschudi et al., 2019). The location data of the passively drifting collars is available at https://doi.org/10.7939/dvn/kuiz7g (Derocher, 2020).

Video supplement. The animation depicting the motion of five dropped telemetry collars in Hudson Bay, Canada, is available at https://doi.org/10.5446/45186 (Togunov et al., 2020).

Author contributions. RRT identified the drifting collars. RRT and NJK designed the study and conducted the analyses with contributions from MAM and AED. NJL and AED conducted field work with assistance from RRT and NJK. RRT prepared the manuscript with contributions from all authors.

Competing interests. The authors declare that they have no conflict of interest.

Acknowledgements. Financial and logistical support of this study was provided by the Canadian Association of Zoos and Aquariums, the Canadian Research Chairs Program, the Churchill Northern Studies Centre, Canadian Wildlife Federation, Care for the Wild International, Earth Rangers Foundation, Environment and Climate Change Canada, Hauser Bears, the Isdell Family Foundation, Kansas City Zoo, Manitoba Sustainable Development, Parks Canada Agency, Pittsburgh Zoo Conservation Fund, Polar Bears International, Quark Expeditions, Schad Foundation, Sigmund Soudack \& Associates Inc., Wildlife Media Inc., and World Wildlife Fund Canada.

Financial support. This research has been supported by the Natural Sciences and Engineering Research Council of Canada (grant nos. 305472-08, 305472-2013, 261231-2013, 261231-2004, 261231-03, 2019-04270, and RGPIN-2017-03867) and the Canada Research Chairs (grant no. CRC-RS 950-231697).

Review statement. This paper was edited by Ted Maksym and reviewed by two anonymous referees.

\section{References}

Auger-Méthé, M., Lewis, M. A., and Derocher, A. E.: Home ranges in moving habitats: Polar bears and sea ice, Ecography, 39, 2635, https://doi.org/10.1111/ecog.01260, 2016a.

Auger-Méthé, M., Field, C., Albertsen, C. M., Derocher, A. E., Lewis, M. A., Jonsen, I. D., and Flemming, J. M.: Statespace models' dirty little secrets: Even simple linear Gaussian models can have estimation problems, Sci. Rep., 6, 26677, https://doi.org/10.1038/srep26677, 2016 b.
Bai, X., Hu, H., Wang, J., Yu, Y., Cassano, E., and Maslanik, J.: Responses of surface heat flux, sea ice and ocean dynamics in the Chukchi-Beaufort sea to storm passages during winter 2006/2007: A numerical study, Deep.-Sea Res. Pt. I, 102, 101117, https://doi.org/10.1016/j.dsr.2015.04.008, 2015.

Bouillon, S. and Rampal, P.: On producing sea ice deformation data sets from SAR-derived sea ice motion, The Cryosphere, 9, 663673, https://doi.org/10.5194/tc-9-663-2015, 2015.

Breslow, N. E. and Clayton, D. G.: Approximate inference in generalized linear mixed models, J. Am. Stat. Assoc., 88, 9-25, https://doi.org/10.2307/2290687, 1993.

Castro de la Guardia, L., Myers, P. G., Derocher, A. E., Lunn, N. J., and Terwisscha Van Scheltinga, A. D.: Sea ice cycle in western Hudson Bay, Canada, from a polar bear perspective, Mar. Ecol. Prog. Ser., 564, 225-233, https://doi.org/10.3354/meps11964, 2017.

Cressie, N., Calder, C. A., Clark, J. S., Ver Hoef, J. M., and Wikle, C. K.: Accounting for uncertainty in ecological analysis: the strengths and limitations of hierarchical statistical modeling NOEL, Ecol. Appl., 19, 553-570, 2009.

Danielson, E. W.: Hudson Bay ice conditions, Arctic, 24, 90-107, 1971.

D'Eon, R. G., Serrouya, R., Smith, G., and Kochanny, C. O.: GPS radiotelemetry error and bias in mountainous terrain, Wildlife Soc. B., 30, 430-439, 2002.

Derocher, A.: Replication Data for: Opportunistic evaluation of modelled sea ice drift using passively drifting telemetry collars in Hudson Bay, Canada, UAL Dataverse, V1, https://doi.org/10.7939/DVN/KUIZ7G, 2020.

Durner, G. M., Douglas, D. C., Albekeke, S. E., Whiteman, J. P., Amstrup, S. C., Richardson, E. S., Wilson, R. R., and Merav, B.D.: Increased Arctic sea ice drift alters adult female polar bear movements and energetics, Glob. Change Biol., 23, 3460-3473, 2017.

Fissel, D. B. and Tang, C. L.: Response of sea ice drift to wind forcing on the northeastern Newfoundland Shelf, J. Geophys. Res., 96, 18397-18409, https://doi.org/10.1029/91jc01841, 1991.

Goto, Y., Yoda, K., and Sato, K.: Asymmetry hidden in birds' tracks reveals wind, heading, and orientation ability over the ocean, Sci. Adv., 3, e1700097, https://doi.org/10.1126/sciadv.1700097, 2017.

Harcourt, R. G., Sequeira, A. M. M., Zhang, X., Roquet, F., Komatsu, K., Heupel, M., McMahon, C., Whoriskey, F., Meekan, M., Carroll, G., Brodie, S., Simpfendorfer, C., Hindell, M., Jonsen, I., Costa, D. P., Block, B., Muelbert, M., Woodward, B., Weise, M., Aarestrup, K., Biuw, M., Boehme, L., Bograd, S. J., Cazau, D., Charrassin, J.-B., Cooke, S. J., Cowley, P., de Bruyn, P. J. N., Jeanniard du Dot, T., Duarte, C., Eguíluz, V. M., Ferreira, L. C., Fernández-Gracia, J., Goetz, K., Goto, Y., Guinet, C., Hammill, M., Hays, G. C., Hazen, E. L., Hückstädt, L. A., Huveneers, C., Iverson, S., Jaaman, S. A., Kittiwattanawong, K., Kovacs, K. M., Lydersen, C., Moltmann, T., Naruoka, M., Phillips, L., Picard, B., Queiroz, N., Reverdin, G., Sato, K., Sims, D. W., Thorstad, E. B., Thums, M., Treasure, A. M., Trites, A. W., Williams, G. D., Yonehara, Y., and Fedak, M. A.: Animal-borne telemetry: An integral component of the ocean observing toolkit, Front. Mar. Sci., 6, 326, https://doi.org/10.3389/fmars.2019.00326, 2019. 
Heil, P., Fowler, C. W., Maslanik, J. A., Emery, W. J., and Allison, I.: A comparison of East Antarctic sea-ice motion derived using drifting buoys and remote sensing, Ann. Glaciol., 52, 103-110, 2001.

Hop, H. and Pavlova, O.: Distribution and biomass transport of ice amphipods in drifting sea ice around Svalbard, Deep-Sea Res. Pt. II, 55, 2292-2307, https://doi.org/10.1016/j.dsr2.2008.05.023, 2008.

Hunke, E. C., Lipscomb, W. H., and Turner, A. K.: Sea-ice models for climate study: retrospective and new directions, J. Glaciol., 56, 1162-1172, 2010.

Hutchings, J. K. and Rigor, I. G.: Role of ice dynamics in anomalous ice conditions in the Beaufort Sea during, J. Geophys. Res, 117, C00E04, https://doi.org/10.1029/2011JC007182, 2012.

Hwang, B.: Inter-comparison of satellite sea ice motion with drifting buoy data, Int. J. Remote Sens., 34, 8741-8763, https://doi.org/10.1080/01431161.2013.848309, 2013.

IABP: International Arctic Buoy Program - Animated Buoy Movies, Univ. Washingt., available at: http: //iabp.apl.washington.edu/data_movie.html, last access: 9 April 2020.

Jaeger, B. C., Edwards, L. J., Das, K., and Sen, P. K.: An R2 statistic for fixed effects in the generalized linear mixed model, J. Appl. Stat., 44, 1086-1105, https://doi.org/10.1080/02664763.2016.1193725, 2017.

Johansson, A. M. and Berg, A.: Agreement and complementarity of sea ice drift products, IEEE J. Sel. Top. Appl., 9, 369-380, https://doi.org/10.1109/JSTARS.2015.2506786, 2016.

Karlsson, S.: Arctic sea ice drift: A comparison of modeled and remote sensing data, BSc Thesis, Department of Physics, Lund University, 2016.

Kimura, N. and Wakatsuchi, M.: Relationship between sea-ice motion and geostraphic wind in the Northern Hemisphere, Geophys. Res. Lett., 27, 3735-3738, https://doi.org/10.1029/2000GL011495, 2000.

Klappstein, N. J., Togunov, R. R., Lunn, N. J., Reimer, J. R., and Derocher, A. E.: Patterns of ice drift and polar bear (Ursus maritimus) movement in Hudson Bay, Mar. Ecol. Prog. Ser., 641, 227-240, 2020.

Kohlbach, D., Lange, B. A., Schaafsma, F. L., David, C., Vortkamp, M., Graeve, M., van Franeker, J. A., Krumpen, T., and Flores, H.: Ice algae-produced carbon is critical for overwintering of antarctic krill Euphausia superba, Front. Mar. Sci., 4, 310, https://doi.org/10.3389/fmars.2017.00310, 2017.

Kwok, R., Spreen, G., and Pang, S.: Arctic sea ice circulation and drift speed: Decadal trends and ocean currents, J. Geophys. Res.Oceans, 118, 2408-2425, https://doi.org/10.1002/jgrc.20191, 2013.

Lavergne, T.: Validation and Monitoring of the OSI SAF Low Resolution Sea Ice Drift Product, Technical report, EUMETSAT Network of Satellite Application Facilities, available at: http://osisaf.met.no/docs/osisaf_cdop2_ss2_valrep_ sea-ice-drift-lr_v5p0.pdf (last access: 10 June 2016), 2016.

Linow, S., Hollands, T., and Dierking, W.: An assessment of the reliability of sea-ice motion and deformation retrieval using SAR images, Ann. Glaciol., 56, 229-234, https://doi.org/10.3189/2015AoG69A826, 2015.

Mahoney, A. R., Hutchings, J. K., Eicken, H., and Haas, C.: Changes in the thickness and circulation of multiyear ice in the Beaufort gyre determined from pseudo-Lagrangian methods from 2003-2015, J. Geophys. Res.-Oceans, 124, 5618-5633, https://doi.org/10.1029/2018jc014911, 2019.

Marcq, S. and Weiss, J.: Influence of sea ice lead-width distribution on turbulent heat transfer between the ocean and the atmosphere, The Cryosphere, 6, 143-156, https://doi.org/10.5194/tc6-143-2012, 2012.

Mauritzen, M., Derocher, A. E., Pavlova, O., and Wiig, Ø.: Female polar bears, Ursus maritimus, on the Barents Sea drift ice: walking the treadmill, Anim. Behav., 66, 107-113, https://doi.org/10.1006/anbe.2003.2171, 2003.

Meier, W. N., Maslanik, J. A., and Fowler, C. W.: Error analysis and assimilation of remotely sensed ice motion within an Arctic sea ice model, J. Geophys. Res.-Oceans, 105, 3339-3356, https://doi.org/10.1029/1999jc900268, 2000.

Miyazawa, Y., Guo, X., Varlamov, S. M., Miyama, T., Yoda, K., Sato, K., Kano, T., and Sato, K.: Assimilation of the seabird and ship drift data in the north-eastern sea of Japan into an operational ocean nowcast/forecast system, Sci. Rep., 5, 17672, https://doi.org/10.1038/srep17672, 2015.

Øigård, T. A., Haug, T., Nilssen, K. T., and Salberg, A. B.: Estimation of pup production of hooded and harp seals in the Greenland Sea in 2007: Reducing uncertainty using generalized additive models, J. Northwest Atl. Fish. Sci., 42, 103-123, https://doi.org/10.2960/J.v42.m642, 2010.

Onodera, J., Watanabe, E., Harada, N., and Honda, M. C.: Diatom flux reflects water-mass conditions on the southern Northwind Abyssal Plain, Arctic Ocean, Biogeosciences, 12, 1373-1385, https://doi.org/10.5194/bg-12-1373-2015, 2015.

Overland, J. E. and Pease, C. H.: Modeling ice dynamics of coastal seas, J. Geophys. Res.-Oceans, 93, 15619-15637, https://doi.org/10.1029/JC093iC12p15619, 1988.

Peeken, I., Primpke, S., Beyer, B., Gütermann, J., Katlein, C., Krumpen, T., Bergmann, M., Hehemann, L., and Gerdts, G.: Arctic sea ice is an important temporal sink and means of transport for microplastic, Nat. Commun., 9, 1505, https://doi.org/10.1038/s41467-018-03825-5, 2018.

Rabinovich, A. B., Shevchenko, G. W., and Thomson, R. E.: Sea ice and current response to the wind: A vector regressional analysis approach, J. Atmos. Ocean. Tech., 24, 1086-1101, https://doi.org/10.1175/JTECH2015.1, 2007.

Rampal, P., Weiss, J., and Marsan, D.: Positive trend in the mean speed and deformation rate of Arctic sea ice, 1979-2007, J. Geophys. Res.-Oceans, 114, C005066, https://doi.org/10.1029/2008JC005066, 2009.

R Core Team: R: A language and environment for statistical computing, available at: https://www.r-project.org/ (last access: 10 June 2020), 2019.

Reichle, R. H.: Data assimilation methods in the Earth sciences, Adv. Water Resour., 31, 1411-1418, https://doi.org/10.1016/j.advwatres.2008.01.001, 2008.

Rozman, P., Hölemann, J. A., Krumpen, T., Gerdes, R., Köberle, C., Lavergne, T., Adams, S., and Girard-Ardhuin, F.: Validating satellite derived and modelled sea-ice drift in the Laptev Sea with in situ measurements from the winter of 2007/08, Polar Res., 30, 7218, https://doi.org/10.3402/polar.v30i0.7218, 2011.

Ruslan, M. I.: Verification of sea ice drift data obtained from remote sensing information, in: IGARSS, IEEE, Valencia, Spain, 7344 7347, 2018. 
Sandvik, B.: World Borders Dataset, Themat. Mapp., available at: http://thematicmapping.org/downloads/world_borders.php (last access: 21 January 2020), 2009.

Saucier, F. J., Senneville, S., Prinsenberg, S., Roy, F., Smith, G., Gachon, P., Caya, D., and Laprise, R.: Modelling the sea ice-ocean seasonal cycle in Hudson Bay, Foxe Basin and Hudson Strait, Canada, Clim. Dynam., 23, 303-326, https://doi.org/10.1007/s00382-004-0445-6, 2004.

Schwegmann, S., Haas, C., Fowler, C. W., Gerdes, R., Heil, P., Fowler, C. W., Maslanik, J. A., Emery, W. J., and Allison, I.: A comparison of satellite-derived sea-ice motion with drifting-buoy data in the Weddell Sea, Antarctica, Ann. Glaciol., 52, 103-110, https://doi.org/10.3189/172756411795931813, 2011.

Stewart, D. B. and Barber, D. G.: The ocean-sea ice-atmosphere system of the Hudson Bay Complex, in: A Little Less Arctic: Top Predators in the World's Largest Northern Inland Sea, Hudson Bay, edited by: Ferguson, S. H., Loseto, L. L., and Mallory, M. L., Springer, New York, NY, USA, 1-37, 2010.

Stirling, I., Spencer, C., and Andriashek, D. S.: Immobilization of polar bears (Ursus maritimus) with Telazol ${ }^{\circledR}$ in the Canadian Arctic, J. Wildlife Dis., 25, 159-168, https://doi.org/10.7589/0090-3558-25.2.159, 1989.

Sumata, H., Lavergne, T., Girard-Ardhuin, F., Kimura, N., Tschudi, M. A., Kauker, F., Karcher, M., and Gerde, R.: An intercomparison of Arctic ice drift products to deduce uncertainty estimates, J. Geophys. Res.-Oceans, 119, 2121-2128, https://doi.org/10.1002/jgrc.20224, 2014.

Sumata, H., Gerdes, R., Kauker, F., and Karcher, M.: Empirical error functions for monthly mean Arctic seaice drift, J. Geophys. Res.-Oceans, 120, 7450-7475, https://doi.org/10.1002/jgrc.20224, 2015a.

Sumata, H., Kwok, R., Udiger Gerdes, R., Kauker, F., Karcher, M., Gerdes, R., Kauker, F., and Karcher, M.: Uncertainty of Arctic summer ice drift assessed by high-resolution SAR data, J. Geophys. Res.-Oceans, 120, 2121-2128, https://doi.org/10.1002/jgrc.20224, 2015b.

Szanyi, S., Lukovich, J. V., Barber, D. G., and Haller, G.: Persistent artifacts in the NSIDC ice motion data set, Geophys. Res. Lett., 43, 10800-10807, https://doi.org/10.1002/2016GL069799, 2016.

Thorndike, A. S. and Colony, R.: Sea ice motion in response to geostrophic winds, J. Geophys. Res., 87, 5845, https://doi.org/10.1029/jc087ic08p05845, 1982.

Thorpe, S. E., Murphy, E. J., and Watkins, J. L.: Circumpolar connections between Antarctic krill (Euphausia superba Dana) populations: Investigating the roles of ocean and sea ice transport, Deep-Sea Res. Pt. I, 54, 792-810, https://doi.org/10.1016/j.dsr.2007.01.008, 2007.

Titchner, H. A. and Rayner, N. A.: The Met Office Hadley Centre sea ice and sea surface temperature data set, version 2: 1 . Sea ice concentrations, J. Geophys. Res.-Atmos., 119, 2864-2889, https://doi.org/10.1002/2014JD021606, 2014.

Tivy, A., Howell, S. E. L., Alt, B., McCourt, S., Chagnon, R., Crocker, G., Carrieres, T., and Yackel, J. J.: Trends and variability in summer sea ice cover in the Canadian Arctic based on the Canadian Ice Service Digital Archive, 19602008 and 1968-2008, J. Geophys. Res.-Oceans, 116, C03007, https://doi.org/10.1029/2009JC005855, 2011.
Togunov, R. R., Derocher, A. E., and Lunn, N. J. N. J.: Windscapes and olfactory foraging in a large carnivore, Sci. Rep., 7, 46332, https://doi.org/10.1038/srep46332, 2017.

Togunov, R. R., Derocher, A. E., and Lunn, N. J.: Corrigendum: Windscapes and olfactory foraging in a large carnivore (Scientific Reports https://doi.org/10.1038/srep46332, Sci. Rep., 8, 46968, https://doi.org/10.1038/srep46968, 2018.

Togunov, R. R., Klappstein, N. J., Derocher, A. E., Lunn, N. J., and Auger-Méthé, M.: Hudson Bay - 2009 - Drifting collar telemetry, https://doi.org/10.5446/45186, 2020.

Tschudi, M. A., Fowler, C. W., Maslanik, J. A., and Stroeve, J.: Tracking the movement and changing surface characteristics of Arctic sea ice, IEEE J. Sel. Top. Appl., 3, 536-540, https://doi.org/10.1109/JSTARS.2010.2048305, 2010.

Tschudi, M. A., Fowler, C. W., Maslanik, J. A., Stewart, J. S., and Meier, W.: Polar Pathfinder daily $25 \mathrm{~km}$ EASE-Grid Sea Ice motion vectors, version 3. National Snow and Ice Data Center Distributed Active Archive Center, NASA Natl. Snow Ice Data Cent. Distrib. Act. Arch. Cent., available at: https://nsidc.org/ data/nsidc-0116/versions/3 (last access: 19 October 2019), 2016.

Tschudi, M. A., Meier, W. N., Stewart, J. S., Fowler, C., and Maslanik, J.: Polar Pathfinder Daily $25 \mathrm{~km}$ EASE-Grid Sea Ice Motion Vectors, Version 4, Boulder, Colorado USA, NASA Nat. Snow Ice Data Cent. Dist. Act. Arch. Cent., https://doi.org/10.5067/INAWUWO7QH7B, 2019.

Tschudi, M. A., Meier, W. N., and Stewart, J. S.: An enhancement to sea ice motion and age products at the National Snow and Ice Data Center (NSIDC), The Cryosphere, 14, 1519-1536, https://doi.org/10.5194/tc-14-1519-2020, 2020.

Vacquie-Garcia, J., Lydersen, C., Biuw, M., Haug, T., Fedak, M. A., and Kovacs, K. M.: Hooded seal Cystophora cristata foraging areas in the Northeast Atlantic Ocean-Investigated using three complementary methods, Plos, 12, e0187889, https://doi.org/10.1371/journal.pone.0187889, 2017.

Venables, W. N. and Ripley, B. D.: Modern Applied Statistics with S, 4th Edn., Springer-Verlag, New York, 2002.

Volkov, V. À., Demchev, D. M. and Ivanov, N. E.: Validation of the model obtained ice drift fields based on satellite derived data using a vector correlation indexes in an invariant form, J. Shipp. Ocean Eng., 7, 250-261, https://doi.org/10.17265/21595879/2017.06.003, 2017.

Willmes, S., Haas, C., Nicolaus, M., and Bareiss, J.: Satellite microwave observations of the interannual variability of snowmelt on sea ice in the Southern Ocean, J. Geophys. Res.-Oceans, 114, C03006, https://doi.org/10.1029/2008JC004919, 2009.

Yoda, K., Shiomi, K., and Sato, K.: Foraging spots of streaked shearwaters in relation to ocean surface currents as identified using their drift movements, Prog. Oceanogr., 122, 54-64, https://doi.org/10.1016/j.pocean.2013.12.002, 2014.

Yonehara, Y., Goto, Y., Yoda, K., Watanuki, Y., Young, L. C., Weimerskirch, H., Bost, C. A., and Sato, K.: Flight paths of seabirds soaring over the ocean surface enable measurement of fine-scale wind speed and direction, P. Natl. Acad. Sci. USA, 113, 9039-9044, https://doi.org/10.1073/pnas.1523853113, 2016. 